\title{
IL-22 and ACPA Levels and their Relationship to the Disease Activity in Rheumatoid Arthritis Patients
}

\section{Khater $\mathrm{ES}^{1 *}$ and Sheik MFA ${ }^{2}$}

${ }^{1}$ Microbiology \& Immunology Department, Benha University, Egypt

${ }^{2}$ Medicine Department, Al Quwayiya General Hospital, Egypt

*Corresponding author: Enas Sh Khater, Microbiology \& Immunology Department, Benha University, Egypt, Email: Drenaskhater@yahoo.com

\section{Research Article}

Volume 6 Issue 1

Received Date: March 03, 2021

Published Date: March 11, 2021

DOI: $10.23880 /$ oajmb-16000185

\section{Abstract}

Aim: to determine ACPA IgG and IL-22 levels in RA patients and their relationship to the disease activity Place and duration of the study: A cross sectional study and prospective cohort study was performed from August 2020 to January 2021 in rheumatology outpatient clinic and laboratory of Al- Quwayiyah General hospital.

Methodology: Forty five rheumatoid arthritis patients were included and 35 healthy participants free of any diseases considered as control group. The patients in this study met the American College of Rheumatology's 2010 guidelines. RA Disease activity was assessed for rheumatoid patients using DAS28 scoring. Serum samples collected from the patients and control to perform ESR, Hs-CRP, RF factors and also IL22 and ACPA IgG which were detected using sandwich ELISA and indirect solid phase enzyme immunoassay techniques respectively.

Results: Out of the 45 RA patients, 34(75.6\%) were females and 11(24.4\%) were males aged from (28-67years) with median patient age 42 years. There was no statistically significant difference regarding age and sex between RA patients and control. Thirty (66.7\%) of the 45 RA patients had low disease activity or remission, while $15(33.3 \%)$ had moderate to extreme disease activity. Thirty two 32(71.1\%) patients of the 45 RA patients had erosive disease. The level of ESR, hs-CRP and RF are increased in the patient group than control, in spite that there were significant differences in the Mean \pm SD among RA group and control group regarding RF, there was no significant statistical differences ESR, hs-CRP. in the study there was an increase in ACPA and IL-22 levels in patients suffering of RA; $21.52 \pm 1.29 \mathrm{U} / \mathrm{ml}$ and $71.22 \pm 10.63 \mathrm{pg} \backslash \mathrm{ml}$. respectively. While among control there was low serum levels; $14.06 \pm 2.01 \mathrm{U} / \mathrm{ml} 33.25 \pm 2.41 \mathrm{pg} \backslash \mathrm{ml}$ and respectively. Significant statistical difference was observed regarding IL-22 and ACPA IgG levels among RA patients and control ( $\mathrm{P}=0.038$ and $\mathrm{P}=0.019$ respectively). There is a significant positive relationship (positive correlation) detected between ACPA and IL-22 levels, $(r=-0.810 ; p=0.597)$. The levels of IL-22 and ACPA were significantly associated with DAS 28. Their relationship was strong as the $r$ value was 0.427 and 0.411 respectively.

Conclusion: IL-22 and ACPA IgG levels were highly increased among RA patients in comparison to the control group. The IL-22 and ACPA IgG levels were strongly correlated with the rheumatoid disease activity, DAS 28. These results suggest that Il-22 can be used in association with ACPA IgG level as diagnostic and prognostic markers of rheumatoid arthritis

Keywords: IL-22; ACPA; Autoimmune Disease; RA

Abbreviations: RA:RheumatoidArthritis;RF: Rheumatoid Factor; NK: Natural Killer; ACPA: Anti-Citrullinated Protein Antibodies; ESR: Erythrocyte Sedimentation Rate; CRP:
Serum Reactive Protien; ACP: Against Citrullinated Proteins; OD: Optical Density. 


\section{Open Access Journal of Microbiology \& Biotechnology}

\section{Introduction}

Rheumatoid arthritis (RA) is a systemic chronic inflammatory autoimmune disease that affects the joints causing synovial proliferation and progressive damage of cartilages and bones [1]. Many risk factors are associated with RA, such as genetic, environmental factors and lifestyle. However, the underlying pathogenic processes are still not well understood [2]. Cytokines are mainly enrolled in the pathogenesis of RA as part of special immunological processes that cause autoimmunity, chronic inflammation and tissue destruction [3]. T cell activation and migration has a key role in the RA pathogenesis. All subsets of T cell participate in immune interactions that preceded development and chronicity of RA [4]. Th1/Th2 and Th17/Treg cell imbalances can play a role in the initiation and progression of RA [5]. Th1 and Th17 cells play a pro-inflammatory role and are responsible for a lot of inflammatory disorders in humans and also mice [6,7], while Th2 and Treg cells have anti-inflammatory role. Anti-citrullinated protein antibodies (ACPA) and rheumatoid factor (RF) are antibodies which are associated with RA and mostly used to diagnose, classify and predict RA disease severity, indicating a pathogenic role in RA. ACPA identifies citrulline which is formed from arginine amino acid residues by effect of peptidyl arginine deiminase enzymes during inflammation [8]. ACPA is a powerful biomarker especially in very early stage and once formed it will not be disappeared from patient serum, its high levels indicate a worse prognosis with progressive erosive damage [9].

Interleukin 22(IL-22) is a part of the IL-10 family which is formed in many cells, including mostly CD4+ T-cells and natural killer (NK) cells. IL-22 has a role in protecting tissue from damage and regulating inflammation and autoimmunity [10]. IL-22 attached to a unique receptor formed of the IL10R2 and IL-22R1.The IL-22R1 part is highly presented in the skin, kidney and synovial fibroblasts. IL-22 bind to IL22R1 activating STAT3 signaling protein kinase pathways [11]. IL-22 is involved in the formation of anti-inflammatory proteins like IL-11, and the expression of pro inflammatory cytokines, likeIL- 6 and acute-phase reactants cytokines. The increased levels of plasma IL-22 are observed in rheumatoid arthritis patients and indicating disease severity [12]. This study aimed to determine IL-22 and ACPA IgG levels in rheumatoid arthritis patients and their relationship to the disease activity.

\section{Materials and Methods}

\section{Study Design}

A cross sectional study and prospective cohort study was performed from August 2020 to January 2021 in the rheumatology clinic and laboratory of Al Quwayiyah General hospital. The patients in this study met the American College of Rheumatology's 2010 guidelines. For RA [13] and should be aged 18 years or more. Patients that were pregnant, had other autoimmune disorders such as Crohn's disease, patients with active infection and cancer patients should be excluded from this study. Patients included both the cases diagnosed prior to the visit and the newly diagnosed. DAS 28 (disease activity score in 28 joints; according to the number of joints with tenderness and swelling) was used to determine all patients' Disease Activity. A score of 3.2 on the DAS 28 indicates moderate to extreme disease activity, while a score of 3.2 indicates low disease activity or remission [14]. Forty five patients with rheumatoid arthritis were enrolled in the study, their age ranged from (28-67years) with median patient age 42 years and 35 healthy individuals as control. Control group include 24 females and 11 males aged (26-65) with median patient age 41 years. After patient permission, clinical and demographic data, including age, sex, and medications, were obtained.

\section{Samples Collection}

Whole blood specimens are collected from each patient using suitable techniques. The blood was allowed to clot and centrifuged to separate the serum. Serum should be clear with no haemolysis or lipemia that may interfere with the procedures. Serum samples could be held in refrigerator for up to five days at $2-8^{\circ} \mathrm{C}$ or stored at $-20^{\circ} \mathrm{C}$ until used.

\section{The Erythrocyte Sedimentation Rate (ESR)} [15].

ESR was done using the standard Westergren method

\section{Serum Reactive Protein (CRP)}

CRP was carried out by using CRP latex test, Crescent diagnostics, UK, Latex particles coated with goat IgG antihuman CRP agglutinated when combined with CRPcontaining samples [16].

\section{Rheumatoid Factor RF}

RF was performed by using QCA RF latex, Crescent diagnostics, UK When latex particles covered with human gamma globulin are combined with RF- containing samples, and an antigen antibody reaction occurs that is readily recognizable due to latex agglutination [17].

\section{Anti-citrullinated Peptide Antibody (ACPA IgG)}

ACPA IgG was performed on Evolis machine using ACPA ELISA kit supplied by Abnova, UK. ACPA IgG was determined 


\section{Open Access Journal of Microbiology \& Biotechnology}

by indirect solid phase enzyme immunoassay for the quantitative measurement of IgG class autoantibodies against citrullinated Proteins (ACP) in human serum. The strength of the yellow color is proportional to the concentration of the antibody-antigen-complex and could be detected photometrically at $450 \mathrm{~nm}$. The range of calculation of this ELISA assay is $0-1000 \mathrm{U} / \mathrm{mL}$ and Cut-off $20 \mathrm{U} / \mathrm{mL}$ [18].

\section{Assay of IL-22}

Serum IL-22 levels were detected using Evolis machine, the human IL-22 ELISA Kit provided by Elabscience Biotechnology Co., the method used was Sandwich-ELISA. The optical density (OD) is measured sphotometrically at $450 \mathrm{~nm} \pm 2 \mathrm{~nm}$ wave lengths. The OD value is correlated to the concentration of IL-22. Calculation of IL-22 concentration in the serum was done by comparison between the OD of the serum samples and the standard curve [19].

\section{Bone Erosions}

Were assessed by a radiology specialist, X-rays for only the hand joints using Larsen Score [20].

\section{Statistical Analysis}

The collected data were analyzed using SPSS version 17 Chicago software. Data was interpreted as numbers and percentages. _ Z" test for 2 variables and " $\chi 2$ (Chi square) test for more than two were used as tests of significance. $\mathrm{P}$ value of $<0.05$ was considered statistically significant.

\section{Results}

Forty five rheumatoid arthritis patients and 35 healthy individuals free of any diseases considered as control group were included in the study. Out of the 45 RA patients, 34 $(75.6 \%)$ were females and $11(24.4 \%)$ were males aged from (28-67years) with median patient age 42 years, and control group included $25(71.4 \%)$ females and $10(28.6 \%)$ males aged (26-65) with median patient age 41 years. There was no statistically significant difference regarding age and sex between RA patients and control, $\mathrm{P}$ value (0.95 and 0.91$)$ respectively. Thirty (33.3\%) of the 45 RA patients had low disease activity or remission, while $15(66.7 \%)$ had moderate to extreme disease activity. Thirty two $32(71.1 \%)$ patients of the 45 RA patients had erosive disease as shown in Table 1.

\begin{tabular}{|c|c|c|c|}
\hline Ch.ch. & Patient group=45 & Control =35 & $P$ value \\
\hline Median age & $42(28-67)$ & $41(26-65)$ & 0.91 \\
\hline Sex & \multicolumn{3}{|c|}{-} \\
\hline Male & $11(24.4 \%)$ & $10(28.6 \%)$ & \multirow{2}{*}{0.95} \\
\hline Female & $34(75.6 \%)$ & $25(71.4 \%)$ & \\
\hline DAS $28<3.2$ high disease activity & $15(25 \%)$ & 0 & 0.28 \\
\hline DAS $28 \geq 3.2$ Low disease activity & $30(75 \%)$ & 0 & \\
\hline Bone erosion Positive & $32(71.1 \%)$ & 0 & 0.009 \\
\hline Negative & $13(28.9 \%)$ & 0 & \\
\hline
\end{tabular}

Table 1: Demographic, clinical and radiological data among patient and control groups.

Table 2 showed that the level of ESR, hs-CRP and RF are increased in the patient group than control, in spite that there were significant differences in the Mean \pm SD among
RA group and control group regarding RF, there was no significant statistical differences for ESR, hs-CRP.

\begin{tabular}{|c|c|c|c|}
\hline Parameters Mean \pm SD & Patient group=45 & Control=35 & P value \\
\hline ESR mm/h & $20.6 \pm 7.5$ & $12 \pm 4.5$ & 0.631 \\
\hline $\mathrm{hs}-\mathrm{CRP} \mathrm{mg} / \mathrm{l}$ & $15.79 \pm 6.45$ & $10.59 \pm 3.81$ & 0.376 \\
\hline $\mathrm{RF} \mathrm{AU} / \mathrm{ml}$ & $388.1 \pm 31.9$ & $12.1 \pm 7.2$ & 0.001 \\
\hline
\end{tabular}

Table 2: Differences in laboratory parameters among RA patient and control groups.

Table 3 showed that there was an increase in ACPA IgG and IL-22 levels in patients suffering of RA; $21.52 \pm 1.29 \mathrm{U} /$ $\mathrm{ml}$ and $71.22 \pm 10 \mathrm{pg} \backslash \mathrm{ml}$. respectively. While among control there was low serum levels; $14.06 \pm 2.01 \mathrm{U} / \mathrm{ml} 33.25 \pm 2.41 \mathrm{pg} \backslash$ $\mathrm{ml}$ and respectively. Significant statistical difference was observed regarding IL-22 and ACPA IgG among RA patients 


\section{Open Access Journal of Microbiology \& Biotechnology}

and control $(\mathrm{P}=0.038$ and $\mathrm{P}=0.019$ respectively $)$.

\begin{tabular}{|c|c|c|c|}
\hline Parameters & Patient group=45 & Control=35 & P value \\
\hline ACPA-IgG (U/ml) & $21.52 \pm 1.29$ & $14.06 \pm 2.01$ & 0.019 \\
\hline IL22 (Pg/ml) & $71.22 \pm 10.63$ & $33.25 \pm 2.41$ & 0.038 \\
\hline
\end{tabular}

Table 3: IL-22and ACPAserum levels among studied groups

There is a significant positive relationship (positive $0.81 ; \mathrm{p}=0.597$ ) as shown in Table 4 . correlation) detected between ACPA and IL-22 levels, ( $r=-$

\begin{tabular}{|c|c|c|c|}
\hline \multicolumn{2}{|c|}{ Correlation Coefficient and P-value } & IL-22 & ACPA IgG \\
\multirow{2}{*}{ IL-22 } & Correlation Coefficient & 1.00 & 0.810 \\
\cline { 2 - 4 } & P-value & - & 0.597 \\
\hline
\end{tabular}

Table 4: Spearman's rho Correlation betweenIL-22 and ACPA IgG serum levels among RA patients.

Figure 1 DAS 28 was found to have a strongly positive association with the levels of IL-22 and ACPA. The relationship was strong, as demonstrated by the $r$ values of 0.427 and 0.411 , respectively. Disease activity was more analysed as variables and it was significant on univariate analysis. The adjusted odds ratio with the 95 per cent confidence interval was determined using the logistic regression model. The levels of IL22 and ACPA IgG were considerably increased in RA patients with moderate to high disease activity $(\mathrm{p}=0.008$ and 0.017 , odds ratio $=1.083$ and $1.074,95 \%$ confidence interval were (1.013-1.150 and 1.001-1.149).
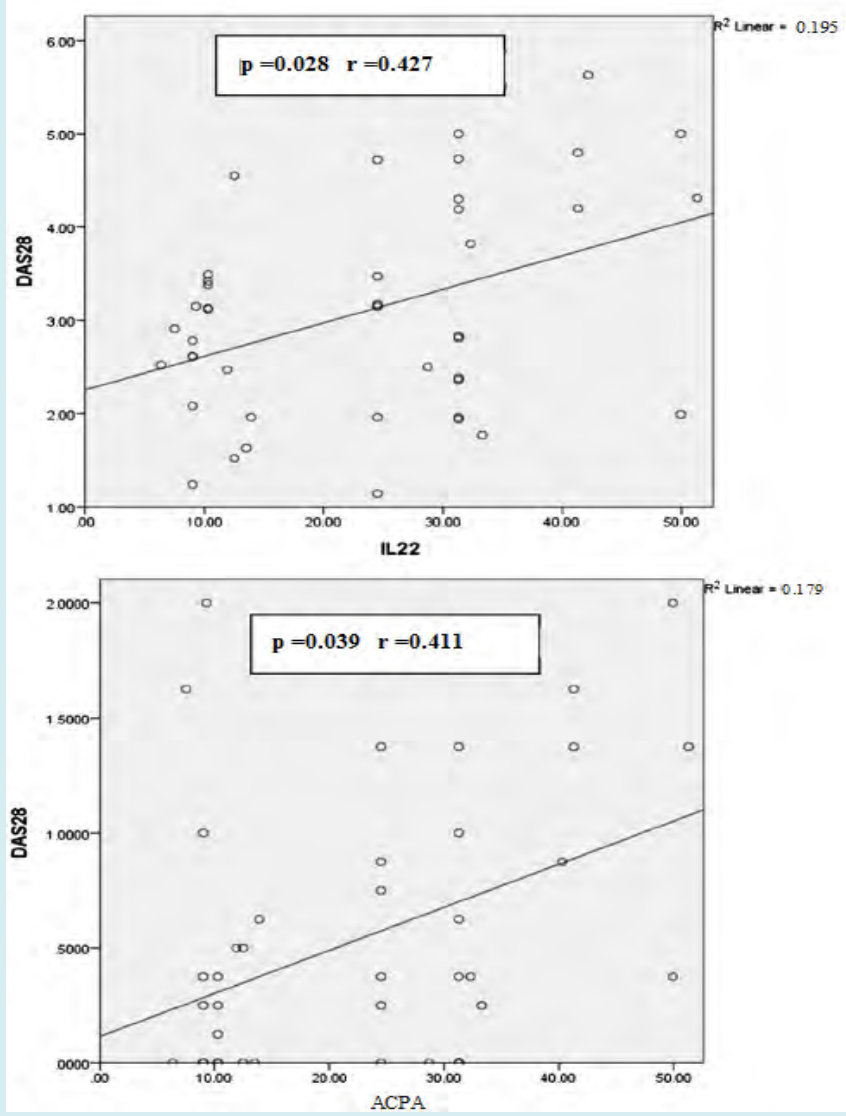

Figure 1: Spearman's rho Correlation between DAS 28 and ACPA \& DAS 28 and IL-22. 


\section{Open Access Journal of Microbiology \& Biotechnology}

\section{Discussion}

Rheumatoid arthritis is an autoimmune and inflammatory disorder that occurs in adults in a percentage of0.5 to $1 \%$ [21]. Forty five rheumatoid arthritis patients were included in the study. Out of the 45 RA patients, 34 (75.6\%) were females and $11(24.4 \%)$ were males aged from (28-67years) with median patient age 42 years. There was no statistically significant difference regarding age and sex between RA patients and control, $P$ value was 0.95 and 0.91 respectively. Moeez, et al. [1] also reported that women are more susceptible to rheumatoid arthritis than males by three times and the disease is highly observed at 30-60 years old patients. Almoallim, et al. [22] found in a study in a tertiary care center in Saudi Arabiathat the mean age of cases was 42.9 years, this matched with the well-established data that patients in their middle to older age are more susceptible to RA. Albishri, et al. [23] also reported that Female more affected $(74.8 \%)$ than males with a ratio of $1: 3$.

In the current study out of the 45 RA patients, $30(66.7 \%)$ of the 45 RA patients had low disease activity or remission, while 15 (33.3\%) had moderate to extreme disease activity. This was agreed with Almoallim, et al. 2020 [22] who found that low disease activity or remission according to the DAS 28 was $79.6 \%$ after one year on therapy while Darawankul, et al.[24] Reported only $14.6 \%$ after 1 year treatment. Other studies reported also $19.6 \%$ and $37 \%$ remission rate. Remission rates were high in this study may be due to earlier detection and good referral systems $[25,26]$. In this work erosive disease was present in 32RA a patient (71.1\%) which was similar to Attarand Al-Ghamd, [27] who stated that radiological changes were detected in $67 \%$ of RA patients, also in Egypt Zayed, et al. [28] reported 75\% erosive changes among their studied RA patients.

In clinical management of RA, CRP and ESR are commonly ordered tests to guide diagnosis of RA besides the measurements of autoantibodies. [29] In this study The level of ESR, hs-CRPand RF are increased in the patient group than control, in spite that there were no significant differences in the Mean \pm SD among RA group and control group regarding ESR, hs-CRP , there was significant differences only in RF levels. Similar finding reported by Suhad, et al. [30] who noted that ESR and h-CRP reactivity was non significantly raised especially in seropositive RA patients. Almoallim and Alharbi, [31] reported that investigations based on lab results, such as the erythrocyte sedimentation rate (ESR) and C-reactive protein (CRP), may not be specific for RA. This lead to the need of more specific tests such as IL-22 and ACPA IgG. Regarding RF also Song and Kang, et al. [32] reported that RF has an important role in the detection and prognosis of patients with arthritis. Van Boekel, et al. [33] also noted that $\mathrm{RF}$ is present in being present in $70-80 \%$ of the RA cases, but may also be detected in also in some autoimmune diseases patients such as Sjögren's syndrome.

For several years, scientists have been studying alternative biologic markers in addition to the clinically used biomarkers. Cytokines act as molecular messengers among cells and play a role in the pathogenesis of RA by activating or controlling immune responses [34].

The present work found that there was an increase in IL-22 and ACPA IgG serum levels in RA group; 68 $\pm 12.78 \mathrm{pg} \backslash$ $\mathrm{ml}$ and $18.89 \pm 2.23 \mathrm{U} / \mathrm{ml}$ respectively. While control group showed low serum levels; $32.10 \pm 4.57 \mathrm{pg} \backslash \mathrm{ml}$ and14.09 \pm 1.86 $\mathrm{U} / \mathrm{ml}$ respectively. It was noticed that among $\mathrm{RA}$ patients and controls, there was a significant difference in IL-22 and ACPA levels. ( $\mathrm{P}=0.038$ and $\mathrm{P}=0.019$ respectively) which was in accordance with the results of Zhao, et al. [35] who reported that the number of circulating Th22, IL-22+Th17, and IL$22+$ Th1 cells and subsequentlyIL-22 levels were significantly higher in RA patients than in controls, indicating that IL-22production enhances the pathogenesis of RA. In the animal model, mice lacking IL-22 had a lower incidence of arthritis and pannus development [36]. Regarding ACPA IgG levels Jarallah, et al. [37] found that serum ACPA IgG levels in RA patients were significantly elevated in RA patients. Molitor, et al. [38] in another study stated that ACPA IgG levels were considerably higher in RA patients. Moreover, in recent years, the relationship between ACPA IgG and RA has gained a lot of attention [39].

In the current study it was noticed that there was a significant positive relationship (positive correlation) detected among ACPA and IL-22 levels, $(r=-0.81 ; p=0.597)$ this was also a finding of al Aldhaher, et al. [40] who reported a correlation betweenIL-22 and ACPA levels. The cause of this association is explained by Clavel, et al. [41,42] that ACPA complexes increase the cytokine production from human macrophages by binding with the $\mathrm{Fc}^{3}$ receptor IIa on macrophages leading to IL-22 release as a result of activation signal.

In this work the levels of IL-22 and ACPA IgG were significantly associated with DAS 28. The mutual relationship was strong as the $r$ value was 0.427 and 0.411 respectively. Hernández, et al. [43] also found that ACPA IgG presence was associated with higher clinical activity and radiographic progression. Zhao, etal. [35] reported that one of the key results of his study was the considerably positive correlation between the IL-22 levels and DAS 28 indicating that the higher IL-22 levels reflect more RA disease activity. Yousef, et al. [19] also demonstrated that IL-22 levels were significantly related to DAS 28 score. These results shed more light on the pathophysiology of RA, implying that IL22 may play a role in RA disease activity and indicating that this cytokine may be 


\section{Open Access Journal of Microbiology \& Biotechnology}

used as a predictor of disease activity [42].

\section{Conclusion}

IL-22 and ACPA IgG levels were highly increased among RA patients in comparison to the control group. The IL-22 and ACPA IgG levels were strongly correlated with the rheumatoid disease activity, DAS 28. These results suggest that Il-22 can be used in association with ACPA IgG level as diagnostic and prognostic markers of rheumatoid arthritis.

\section{References}

1. Moeez S, John P, Bhatti A (2013) Anti-citrullinated protein antibodies: role in pathogenesis of RA and potential as a diagnostic tool. Rheumatol Int 33(7): 1669-1673.

2. Littman DR, Rudensky AY (2010) Th17 and regulatory $\mathrm{T}$ cells in mediating and restraining inflammation. Cell 140(6): 845-858.

3. Choy EH, Panayi GS (2001) Cytokine pathways and joint inflammation in rheumatoid arthritis. $N$ Engl J Med 344(12): 907-916.

4. Wang W, Shao S, Jiao Z, Guo M, Xu H, et al. (2011) The Th17/Treg imbalance and cytokine environment in peripheral blood of patients with rheumatoid arthritis. Rheumatology International 32(4): 887-893.

5. Wolk K, Sabat R (2006) Interleukin-22: A novel T- and NK-cell derived cytokine that regulates the biology of tissue cells. Cytokine Growth Factor Rev 17(5): 367-380.

6. Zenewicz LA, Flavell RA (2011) Recent advances in IL-22 biology. Int Immunol 23(3): 159-163.

7. Tian J, Yong J, Dang H, Kaufman DL (2011) Oral Gaba treatment down regulates inflammatory responses in a mouse model of rheumatoid arthritis. Autoimmunity 44(6): 465-470.

8. Szekanecz Z, Soos L, Szabo Z, Fekete A, Kapítany A, et al. (2008) Anti-Citrulünated Protein Antibodies in Rheumatoid Arthritis: As Good as it Gets? Clin Rev Allergy Immunol 34(1): 26-31.

9. Puszczewicz M, Iwaszkiewicz C (2011) Role of anticitrullinated protein antibodies in diagnosis and prognosis of rheumatoid arthritis. Arch Med Sci 7(2): 189-194.

10. Linsley PS, Nadler SG (2009) The clinical utility of inhibiting cd28-mediated costimulation. Immunol Rev 229(1): 307-321.

11. Sakaguchi S, Benham H, Cope AP, Thomas R (2012) T-cell receptor signaling and the pathogenesis of autoimmune arthritis: Insights from mouse and man. Immunol Cell Biol 90(3): 277-287.

12. Dardalhon V, Korn T, Kuchroo VK, Anderson AC (2008) Role of Th1 and Th17 cells in organ-specific autoimmunity. J Autoimmun 31(3): 252-256.

13. Prevoo ML, van't Hof MA, Kuper HH, van Leeuwen MA, van de Putte LB, et al. (1995) Modified disease activity scores that include twenty-eight-joint counts. Development and validation in a prospective longitudinal study of patients with rheumatoid arthritis. Arthritis Rheum 38(1): 44-48.

14. Mäkinen H, Kautiainen H, Hannonen P, Sokka T (2005) Is DAS28 an appropriate tool to assess remission in rheumatoid arthritis? Ann Rheum Dis 64(10): 14101413.

15. Westergren A (1921) Studies of the suspension stability of blood in pulmonary tuberculosis. Acta Medica 54(1): 247-282.

16. Fisher CL, Nakamura R, Amr J (1976) laboratory medicine immunology. Immunol 20(6): 12-15.

17. Heller G, Jacobson S, Koloday M (1954) The determination of rheumatoid factor. Immunol 6(1): 46-50.

18. Al-Hakeim HK, Moustafa SR, Jasem KM (2019) Serum Cesium, Rhenium, and Rubidium in Rheumatoid Arthritis Patients. Biol Trace Elem Res 189(2): 379-386.

19. Yousef LM, Aboalftoh S, Abdel-Latef TM, Ali KS (2018) The Use of Interleukin-22 as a Novel Marker of Disease Activity in Female Patients with Rheumatoid Arthritis. Sohag Medical Journal 22(1): 143-153.

20. Larsen A (1995) How to apply Larsen Score in evaluating radiographs of rheumatoid arthritis in long term studies? J Rheumatol 22(10): 1974-1975.

21. Aletaha D, Neogi T, Silman AJ, Funovits J, Felson DT, et al. (2010) Rheumatoid arthritis classification criteria: an American College of Rheumatology/ European League Against Rheumatism collaborative initiative. Arthritis Rheum 62(9): 2569-2581.

22. Almoallim H, Hassan R, Cheikh M, Faruqui H, Alquraa R, et al. (2020) Rheumatoid Arthritis Saudi Database (RASD): Disease Characteristics and Remission Rates in a Tertiary Care Center. Open Access Rheumatol 12: 139145.

23. Albishri J, Bukhari M, Alsabban A, Almalki FA, Altwairqi AS (2015) Prevalence of RA and SLE in Saudi Arabia. Sch J App Med Sci 3(5D): 2096-2099. 


\section{Open Access Journal of Microbiology \& Biotechnology}

24. Darawankul B, Chaiamnuay S, Pakchotanon R, Asavatanabodee P, Narongroeknawin P (2015) The good EULAR response at the first year is strongly predictive of clinical remission in reheumatoid arthritis: results from the TARAC cohort. Clin Rheumatol 34(1): 43-49.

25. Mierau M, Schoels M, Gonda G, Fuchs J, Aletaha D, et al. (2007) Assessing remission in cinical practice. Rheumatology (Oxford) 46(6): 975-979.

26. Barnabe C, Homik J, Barr SG, Martin L, Maksymowych WP (2014) The effect of different remission definitions on identification of predictors of both point and sustained remission in rheumatoid arthritis treated with anti-TNF therapy. J Rheumatol 41(8): 1607-1613.

27. Attar SM, Al-Ghamdi A (2010) Radiological changes in rheumatoid arthritis patients at a teaching hospital in Saudi Arabia. Eastern Mediterranean Health Journal 16(9): 953-957.

28. Zayed A, Amer H, Nasar H, Ibrahiem A, Mottawie H (2007) Some biochemical changes in serum and synovial fluid in patients with rheumatoid arthritis. Journal of Medical Science 7(4): 526-535.

29. Nielen MMJ, van Schaardenburg D, Reesink HW, Twisk JWR, van de Stadt RB (2004) Increased levels of C-reactive protein in serum from blood donors before the onset of rheumatoid arthritis. Arthritis Rheum 50(8): 2423-2427.

30. Aubaid Suhad, Ekhlas, Zeina, Donya, Alheidary Suhad (2020) Measuring of Interleukin -22 and IL -17a Levels in Seropositive and Seronegative Rheumatoid Arthritis Patients. Indian Journal of Forensic Medicine \& Toxicology 14: 1921-926.

31. Almoallim HM, Alharbi LA (2014) Rheumatoid arthritis in Saudi Arabia. Saudi Med J 35(12): 1442-1454.

32. Song YW, Kang EH (2010) Autoantibodies in rheumatoid arthritis: rheumatoid factors and anticitrullinated protein antibodies. QJM 103(3): 139-146.

33. Van Boekel MAM, Vossenaar ER, van den Hoogen FHJ, van Venrooji WJ (2002) Autoantibody systems in Rheumatoid arthritis: specificity, sensitivity and diagnostic value. Arthritis Res 4(2): 87-93.
34. Burska M, Boissinot M, Ponchel F (2014) Cytokines as biomarkers in rheumatoid arthritis Mediators of Inflamm 2014: 545493.

35. Zhao L, Jiang Z, Jiang Y, Ma N, Zhang Y, et al. (2013) IL$22+\mathrm{CD} 4+\mathrm{T}$ cells in patients with rheumatoid arthritis. Int J Rheum Dis 16(5): 518-526.

36. Geboes L, Dumoutier L, Kelchtermans H, Schurgers E, Mitera T, et al. (2009) Proinflammatory role of the Th17 cytokine interleukin-22 in collagen-induced arthritis in C57BL/6 mice. Arthritis Rheum 60(2): 390-395.

37. Jarallah FM, Al-Safi K, Al- Ghurabi BH (2015) Evaluation of serum anti-cyclic citrullinated peptide antibodies level in rheumatoid patients with and without periodontitis. J Bagh College Dentistry 24(4): 83-87.

38. Molitor J, Alonso A, Wener M (2009) Moderate to severe adult periodontitis increases risk of rheumatoid arthritis in non-smokers and is associated with elevated ACPA titers: the ARIC study. Arthritis Rheum 60(10): 433-434.

39. Li K, Mo W, Wu L, Wu X, Luo C, et al. (2021) Novel autoantibodies identified in ACPA-negative rheumatoid arthritis. Annals of the Rheumatic Diseases.

40. Aldhaher ZA, Al-Ghurabi BH, Alwan BH (2018) Serum Levels of IL-22 and ACPA in Patients with Rheumatoid Arthritis. Journal of Pure and Applied Microbiology 12(2): 687-691.

41. Clavel C, Nogueira L, Laurent L, Iobagiu C, Vincent $C$, et al. (2008) Induction of macrophage secretion of tumor necrosis factor alpha through Fcy receptor IIa engagement by rheumatoid arthritis-specific autoantibodies to citrullinated proteins complexed with fibrinogen. Arthritis Rheum 58(3): 678-688.

42. Leipe J, Schramm MA, Grunke M, Baeuerle M, Dechant C, et al. (2011) Interleukin 22 serum levels are associated with radiographic progression in rheumatoid arthritis. Ann Rheum Dis 70(8): 1453-1457.

43. Hernandez R, Uceda J, Rodriguez SA, Almeida C, Marenco JL (2015) Disease activity measured by DAS28 in a cohort of 260 patients with rheumatoid arthritis. Are the presences of anti citrullinated peptide antibodies related with trh activity of the disease? Annals of the Rheumatic Diseases 76(S1): A14. 